\title{
Collaboration Leads to Oral Chemotherapy Education
}

\begin{abstract}
ASHLEY E. GLODE, ${ }^{1}$ PharmD, BCOP, LISA HOLLE, ${ }^{2}$ PharmD, BCOP, FHOPA, JOSH NUBLA, ${ }^{3}$ PharmD, MIKE MINJOCK, ${ }^{4}$ NANCY EGERTON, ${ }^{3}$ PharmD, BCOP, KRIS LEFEBVRE, ${ }^{4} \mathrm{MSN}, \mathrm{RN}$, AOCN ${ }^{\circledR}$, MICHAEL REFF, ${ }^{3}$ RPH, MBA, and DAVID DEREMER, ${ }^{5}$ PharmD, BCOP, FCCP
\end{abstract}

From 'Department of Clinical Pharmacy, University of Colorado Skaggs School of Pharmacy and Pharmaceutical Sciences, Aurora, Colorado; 2Department of Pharmacy Practice, University of Connecticut School of Pharmacy, Storrs, Connecticut; ${ }^{3 N a t i o n a l ~ C o m m u n i t y ~ O n c o l o g y ~}$ Dispensing Association, Syracuse, New York; ${ }^{4}$ Oncology Nursing Society, Pittsburgh, Pennsylvania; ${ }^{5}$ University of Florida College of Pharmacy, Gainesville, Florida

Authors' disclosures of conflicts of interest are found at the end of this article.

Correspondence to: Ashley E. Glode, PharmD, BCOP, 12850 E. Montview Blvd, Mail Stop C238, Aurora, Colorado 80045

E-mail: ashlev.glode@ucdenver.edu

https://doi.org/10.6004/jadpro.2018.9.7.7 (c) 2018 Harborside ${ }^{\text {TM }}$

\begin{abstract}
The Association of Community Cancer Centers (ACCC), Hematology/ Oncology Pharmacy Association (HOPA), National Community Oncology Dispensing Association (NCODA), and Oncology Nursing Society (ONS) partnered together to create a resource for providers, and patients and caregivers on oral chemotherapy agents. The patient education sheets include information on medication names and pronunciation, approved uses, dose and schedule, drug and food interactions, the best practice guidelines for safe handling, administration, and disposal of oral chemotherapy agents by patients and caregivers; management strategies for the most common side effects; and pregnancy, sexual activity, and contraception information. Each sheet also has an area to list from which pharmacy the patient will receive the medication. The document and the website also provide the link to the individual product website, prescribing information, and product resources, if available.
\end{abstract}

roviding comprehensive chemotherapy education to patients in a busy clinical practice setting can be challenging. Potential barriers to providing patient education include work overload, low priority, difficulty in communication, insufficient knowledge and skills, and lack of comprehensive tools. Advanced practice providers are often tasked with providing patient education, but may find it difficult to thoroughly cover all important aspects during the education session due to lack of tools that include all essential elements of med- ication education. Advanced practice providers may have personal favorite tools to use or instructional guides that are required by institutions, but it still may be difficult to find an easily accessible, comprehensive, and yet concise resource.

According to the 2016 American Society of Clinical Oncology (ASCO)/Oncology Nursing Society (ONS) Chemotherapy Administration Safety Standards, chemotherapy education should include-at a minimum-11 essential elements (Neuss, 2017). The elements of medicationspecific information that should 
be discussed include the duration of treatment, schedule of administration, drug names and supportive care medications, drug-drug and drugfood interactions, plan for missed doses, serious adverse effects the patient should report right away, in addition to common adverse effects and recommendations for symptom management, procedures for safe storage, handling, and disposal of medications, as well as procedures for handling body secretions and waste in the home.

The Association of Community Cancer Centers (ACCC), Hematology/Oncology Pharmacy Association (HOPA), National Community Oncology Dispensing Association (NCODA), and ONS partnered together to create a resource for providers, and patients and caregivers on oral chemotherapy agents. The multi-association team worked together to create comprehensive PDF documents that may be accessed online free of charge. The PDFs may be edited, then saved and emailed to patients and their caregivers, or may be printed and reviewed with patients in the clinical practice setting. The medication library lists agents by both brand and generic name for ease of use. It also includes the date which the document was last updated so that advanced practice providers can be confident they are providing the most up-to-date information.
The patient education sheets include information on medication names and pronunciation, approved uses, dose and schedule, drug and food interactions, the best practice guidelines for safe handling, administration, and disposal of oral chemotherapy agents by patients and caregivers; management strategies for the most common side effects; and pregnancy, sexual activity, and contraception information. Each sheet also has an area to list from which pharmacy the patient will receive the medication. The document and the website provide the links to the individual product website, prescribing information, and product resources, if available. More information and the entire library of oral chemotherapy education patient education sheets are available online and as PDFs at OralchemoEdSheets.com.

\section{Disclosure}

The authors have no conflicts of interest to disclose.

\section{References}

Neuss, M. N., Gilmore, T. R., Belderson, K. M., Billett, A. L., Conti-Kalchik, T., Harvey, B. E.,...Polovich, M. (2017). 2016 American Society of Clinical Oncology/Oncology Nursing Society Chemotherapy Administration Safety Standards, Including Pediatrics. Oncology Nursing Forum, 44(1), 31-43. https://doi.org/10.1188/17.ONF.31-43 